\title{
COMPARATIVE STUDY ON THREE DOSES OF ESMOLOL TO ATTENUATE THE HAEMODYNAMIC STRESS RESPONSE DURING LARYNGOSCOPY AND ENDOTRACHEAL INTUBATION
}

\author{
L. Raghavan', N. Basker ${ }^{2}$ \\ ${ }^{1}$ Associate Professor, Department of Anaesthesiology, Chengalpattu Medical College. \\ ${ }^{2}$ Associate Professor, Department of Anaesthesiology, Chengalpattu Medical College.
}

\section{ABSTRACT}

\section{BACKGROUND}

The advantage of IV Esmolol due to its ultra-short action seem to be ideal to control intense but brief sympathetic stimulation following endotracheal intubation, inspired us to conduct a study in which we compared the three doses of Esmolol to attenuate the haemodynamic stress response during Laryngoscopy and Endotracheal intubation.

\section{AIM}

This study was done to compare the varying doses of IV Esmolol in attenuating the haemodynamic stress response to laryngoscopy and endotracheal intubation.

\section{METHODS AND MATERIALS}

Sixty ASA I and II patients undergoing elective surgical procedure under general anaesthesia with endotracheal intubation were included in this study. Patients belonging to age group 20-50 years of both the sexes were included. It is prospective double blind randomized study. The study was approved by the Ethical Committee and was randomly grouped into three groups. Group A (Esmolol $5 \mathrm{mg} / \mathrm{kg}$ ) 20 patients were given Esmolol $0.5 \mathrm{mg} / \mathrm{kg}$ IV 2 minutes before intubation. Group B (Esmolol $1.0 \mathrm{mg} / \mathrm{kg}$ ) -20 Patients were given Esmolol $1 \mathrm{mg} / \mathrm{kg}$ IV 2 minutes before intubation. Group C (Esmolol $1.5 \mathrm{mg} / \mathrm{kg}$ ) 20 patients were given Esmolol $1.5 \mathrm{mg} / \mathrm{kg}$ IV 2 minutes before intubation.

\section{STATISTICAL ANALYSIS}

Heart rate, systolic Blood pressure, Diastolic pressure and mean arterial pressure were recorded using MS Excel software and analysed using STATA software for determining the statistical significance. ANOVA test was used to determine the significance among three groups. Student's ' $\mathrm{t}$ ' test was used to compare the three groups in mean values of various parameters. The $P$ value taken for signification is $<0.05$.

\section{RESULTS}

The dose of Esmolol $1.5 \mathrm{mg} / \mathrm{kg}$ (Group C) to be effective in attenuating the haemodynamic responses during laryngoscopy and ET intubation with no major adverse effects when compared to 0.5 and $1.0 \mathrm{mg} / \mathrm{kg}$.

\section{CONCLUSION}

We found that the dose of Esmolol $1.5 \mathrm{mg} / \mathrm{kg}$ (Group C) to be effective in attenuating the haemodynamic responses during laryngoscopy and endotracheal intubation with no major adverse effects of Esmolol.

\section{KEYWORDS}

Haemodynamics, Intubation, Endotracheal, Laryngoscopy, Esmolol.

HOW TO CITE THIS ARTICLE: Raghavan L, Basker N. Comparative study on three doses of esmolol to attenuate the haemodynamic stress response during laryngoscopy and endotracheal intubation. J. Evolution Med. Dent. Sci. 2016;5(49):31163121, DOI: $10.14260 /$ jemds/2016/724

\section{INTRODUCTION}

In 1940, Reid and Brace first described haemodynamic response to laryngoscopy and intubation. Laryngoscopy and endotracheal intubation are mandatory for most patients undergoing general anaesthesia, which is invariably associated with certain cardiovascular changes such as tachycardia or bradycardia, rise in blood pressure and a wide variety of cardiac arrhythmias. These effects are deleterious in susceptible individuals culminating in perioperative myocardial ischaemia, acute heart failure and cerebrovascular accidents.

Financial or Other, Competing Interest: None.

Submission 19-05-2016, Peer Review 30-05-2016,

Acceptance 02-06-2016, Published 17-06-2016.

Corresponding Author:

Dr. L. Raghavan,

\#A-40, Arcot Terrace,

No.160-NSK Salai,

Vadapalani, Chennai-600026.

E-mail: Iraghavan63@gmail.com

DOI: 10.14260/jemds/2016/724
The haemodynamic response to laryngoscopy and endotracheal intubation has been recognized since 1951. The induction of anaesthesia, laryngoscopy and intubation and surgical stimulation often evoke cardiovascular response characterized by alterations in systemic arterial pressure, pulse rate and cardiac rhythm. The response following laryngoscopy and intubation peaks at 1.2 minute and returns to normal within 5-10 minutes.

Though these sympathoadrenal responses are probably of little consequence in healthy individuals, it is hazardous to those patients with hypertension, coronary heart disease, intracranial pathology and hyper-reactive airways. In such cases reflex circulatory responses such as increase in heart rate, systemic arterial blood pressure and disturbances in cardiac rhythm needs to be suppressed. Prof. King et al (1951), documented myocardial ischaemic changes due to reflex sympathoadrenal response immediately following laryngoscopy and intubation with a mean rise in systemic pressure of $40 \mathrm{mmHg}$ even in normotensive individuals. 
Various systemic as well as topical agents were used to reduce these untoward haemodynamic responses due to laryngoscopy and intubation. Those techniques which require prior laryngoscopy to the local anaesthetic solution are likely to be of limited value. The common strategies adopted are narcotics, vasodilators, beta blockers, calcium channel blockers, lidocaine and other sympatholytics.

IV Esmolol due to its ultra-short action seems to be ideal to control intense but brief sympathetic stimulation following endotracheal intubation. The above study was done in the Department of Anaesthesiology, Chengalpattu Medical College, Chengalpattu.

\section{METHODS AND MATERIALS}

Sixty ASA I and II patients undergoing elective surgical procedure under general anaesthesia with endotracheal intubation were included in this study.

Patients belonging to age group 20-50 years of both the sexes were included.

It is prospective double blind randomized study. The study was approved by the Ethical Committee and was randomly grouped into three groups.

Group A: (Esmolol $5 \mathrm{mg} / \mathrm{kg}) 20$ patients were given Esmolol $0.5 \mathrm{mg} / \mathrm{kg}$ IV 2 minutes before intubation.

Group B: (Esmolol $1.0 \mathrm{mg} / \mathrm{kg}$ ) 20 patients were given Esmolol $1 \mathrm{mg} / \mathrm{kg}$ IV 2 minutes before intubation.

Group C: (Esmolol $1.5 \mathrm{mg} / \mathrm{kg}$ ) 20 patients were given Esmolol $1.5 \mathrm{mg} / \mathrm{kg}$ IV 2 minutes before intubation.

The study was done during the period from May 2015 to November 2015 in the Department of Anaesthesiology, Chengalpattu Medical College, Chengalpattu.

\section{Inclusion Criteria}

- $\quad$ ASA I and II.

- Age 20-50 yrs.

- All cases requiring GA.

\section{Exclusion Criteria}

- Difficult intubation cases.

- Esmolol contraindications.

- Not meeting inclusion criteria.

- Patients on beta blockers.

- Patients with full stomach.

- Patients posted for Emergency surgery.

- Hypertension, Diabetes, Ischaemic heart disease.

\section{Pre-0perative Preparation}

All the patients were admitted and they underwent relevant investigations. Preoperatively informed and written consent was obtained from the patient.

\section{Haemogram, Bleeding Time, Clotting Time \\ Blood \\ - Urea. \\ - Sugar.}

\section{Serum}

- Creatinine.

- Electrolytes.

- X-ray Chest.
- Electrocardiogram.

Other relevant investigations were obtained on the basis of the condition of the patient.

\section{Anaesthesia Protocol}

- Pre-Operative visit was done to allay anxiety and good rapport was established with the patient.

- All the patients were given preoperative night sedation with tablet Diazepam $10 \mathrm{mg}$ and antacid prophylaxis with table Ranitidine 150 mg orally.

\section{Premedication}

All the patients were premedicated with Inj. Glycopyrrolate 4 $\mu \mathrm{g} / \mathrm{kg}$ body weight, intramuscularly, 45 minutes before surgery. Basal pulse rate and blood pressure were recorded.

\section{Monitoring}

Patient shifted to operating table after 45 minutes. In the operating room patients were connected to baseline monitors, then intravenous access established with 18-gauge cannula and intravenous fluids started. Pulse rate, Blood pressure, ECG and SpO2 were recorded.

\section{Pre-oxygenation}

Pre-oxygenation was done with $100 \%$ oxygen for 3 minutes.

\section{Administration of Study Drug}

Inj. Fentanyl $2 \mathrm{ug} / \mathrm{kg}$ IV given three minute prior to induction. The study drug was taken in a $20 \mathrm{~mL}$ syringe and diluted to $20 \mathrm{~mL}$ and given as bolus over 15-20 seconds two minutes before intubation. One minute later, anaesthesia was induced with $2.5 \%$ Inj. Thiopentone sodium $5 \mathrm{mg} / \mathrm{kg}$ IV. Inj. Succinylcholine $1.5 \mathrm{mg} / \mathrm{kg}$ IV given. After satisfying muscle relaxation, the patient was intubated with appropriate size endotracheal tube after doing a proper laryngoscopy within 10-15 seconds. Conditions where prolongation of laryngoscopy time due to difficult intubation, these patients were excluded from the study. Endotracheal tube was secured after confirming bilateral air entry. Anaesthesia maintained with $\mathrm{N}_{2} \mathrm{O}$ and $\mathrm{O}_{2}$ (66.7\%: 33.3\%) and IPPV was done. The ETCO2 was maintained at the pressure of 30-35 $\mathrm{mmHg}$. The whole intraoperative and post-operative periods were uneventful.

\section{OBSERVATION AND RESULTS}

Sixty patients under this study were categorized into three groups. They comprised of both sexes with age ranging from 20-50 years.

The age, sex and body mass index were equal in all the three groups. $P$ valve was not significant in the study done ( $p$ $>0.05$ ).

At intake of study, there is no significant difference on age and BMI of patients among the groups.

\section{The Groups are,}

Group A: (Esmolol $0.5 \mathrm{mg} / \mathrm{kg}$ ): Twenty patients were given Esmolol $0.5 \mathrm{mg} / \mathrm{kg}$ IV 2 minutes before intubation as a bolus.

Group B: (Esmolol $1.0 \mathrm{mg} / \mathrm{kg}$ ): Twenty patients were given Esmolol $1 \mathrm{mg} / \mathrm{kg}$ IV 2 minutes before intubation as a bolus.

Group C: (Esmolol $1.5 \mathrm{mg} / \mathrm{kg}$ ): Twenty patients were given Esmolol $1.5 \mathrm{mg} / \mathrm{kg}$ IV 2 minutes before intubation as a bolus. 
Heart rate, systolic blood pressure, diastolic blood pressure and mean arterial pressure were measured before premedication, after premedication, during administration of the study drug, during induction, during intubation, after intubation and following for about 7 minutes after laryngoscopy and intubation for every minute.

Table I, II, III and IV shows the heart rate, systolic blood pressure, diastolic blood pressure and mean arterial pressure comparisons between the three groups.

\begin{tabular}{|c|c|c|c|}
\hline Variables & Group A & Group B & Group C \\
\hline Heart Rate & $18 \%$ & $12 \%$ & $5 \%$ \\
\hline Systolic Blood Pressure & $31 \%$ & $24 \%$ & $18 \%$ \\
\hline Diastolic Blood Pressure & $27 \%$ & $22 \%$ & $17 \%$ \\
\hline Mean Arterial Pressure & $29 \%$ & $22 \%$ & $17 \%$ \\
\hline \multicolumn{2}{|c|}{ Comparison of Variables on the Three Groups } \\
\hline
\end{tabular}

\section{Heart Rate and Rhythm}

In Group A, the rise in heart rate was about $18 \%$ from the baseline values during and following intubation and it took longer time to reach the baseline values. There was a rise of about 16 beats per minute from baseline following laryngoscopy and intubation.

In Group B, there was an initial fall in heart rate following bolus dose of Esmolol and there was a rise of about 8 beats per minute following laryngoscopy and intubation. The rise in heart rate was about $12 \%$ from the baseline following laryngoscopy and intubation. It returned back to baseline value at the sixth minute.

In Group C, the rise in heart rate was modest of about 2-3 beats per minute and the values returned to baseline values at the fourth minute. The rise was $5 \%$ from the baseline values with least fluctuation in heart rate during the study period. There was a decline in heart rate at fourth minute and a further decline was observed at sixth and seventh minute from the baseline values.

There is no statistical significance among the mean value of heart rate at the pre-medication time ( $p>0.05)$. But it is significantly different during administration of Esmolol bolus, induction, intubation during and for about seven minutes following laryngoscopy and intubation. It was significantly lower in Group C than in Groups A and B ( $p<0.001)$. The initial fall in Group B is because of its direct action on cardiac conducting system.

There was no record of arrhythmias in any of the patients in any of the group. This is probably because of all the patients are of ASA Class I and II with no history of hypertension or no other cardiac ailments.

\section{BLOOD PRESSURE}

\section{Systolic Blood Pressure}

There is no statistical significance on mean value among the three groups at pre-medication and during administration of Esmolol bolus ( $p>0.05$ ). But, it is statistically significant on all other period of study ( $p<0.001$ ) in between the three groups. There is $31 \%, 24 \%$ and $18 \%$ increase from baseline during the operation in group $\mathrm{A}$, group $\mathrm{B}$ and group $\mathrm{C}$ respectively. The rise in the systolic blood pressure is comparatively less in Group C from the Groups A and B. Higher mean value reached at intubation in all 3 groups.

\section{Diastolic Blood Pressure}

There is no statistical significance on mean on Diastolic Blood Pressure at Pre-Medication and Esmolol ( $p>0.05$ ). But, it is statistically significant during induction $(\mathrm{P}<0.05)$. It is also statistically significant from the period of intubation to the end of study period ( $\mathrm{p}<0.001$ ). There is up to $27 \%, 22 \%$ and $17 \%$ increase from baseline during the operation in group $\mathrm{A}$ group B and group C respectively. Higher mean value reached at intubation in all the groups.

Mean Arterial Pressure: There is no statistical significance on mean value of MAP up to induction during the period of study ( $p>0.05)$. But it is statistically significant after the induction till the end of the study period $(\mathrm{p}<0.001)$. There is up to $29 \%, 22 \%$ and $17 \%$ increase from baseline during the operation in group A, group B and group C respectively. Higher mean value reached at intubation in all 3 groups.

\section{Statistical Analysis}

Heart rate, systolic blood pressure, diastolic pressure and mean arterial pressure were recorded using MS Excel Software and analysed using STATA software for determining the statistical significance.

ANOVA test was used to determine the significance among three groups. Student's ' $\mathrm{t}$ ' test was used to compare the three groups in mean values of various parameters. The $\mathrm{P}$ value taken for signification is $<0.05$.
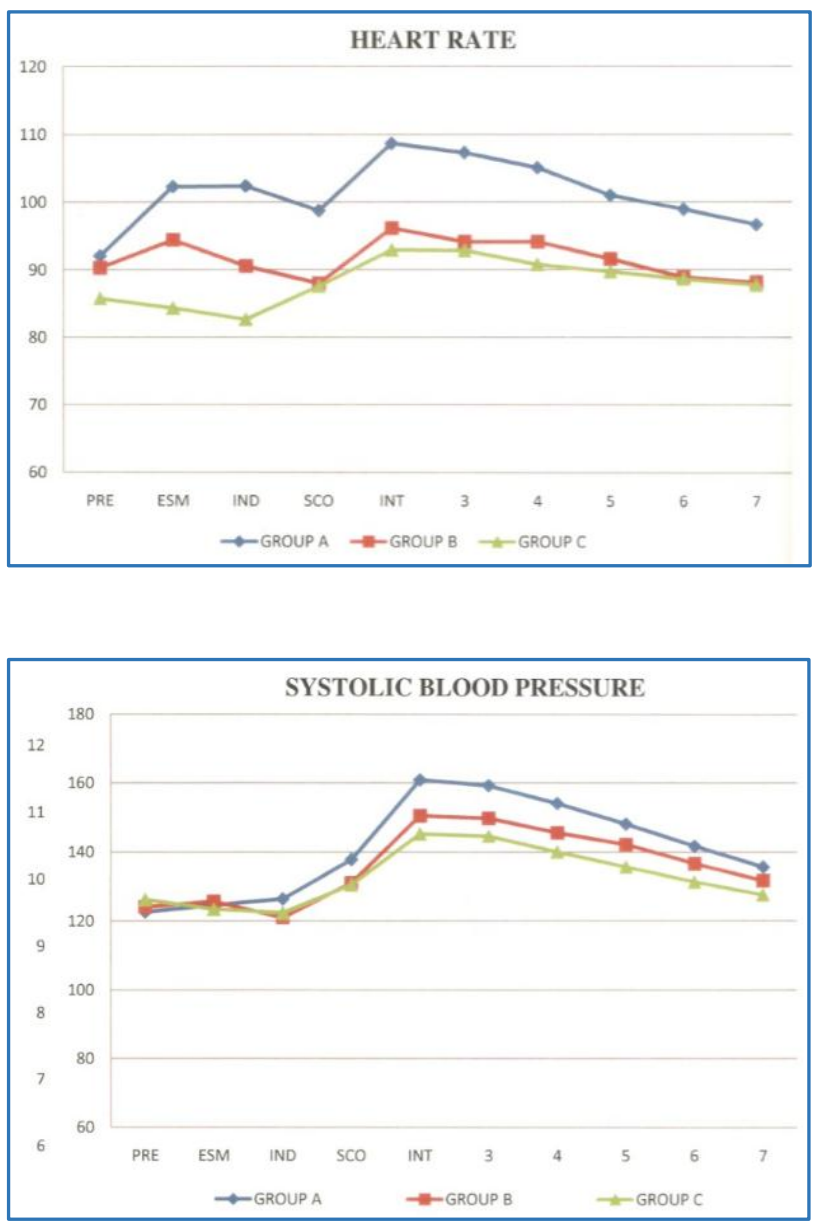

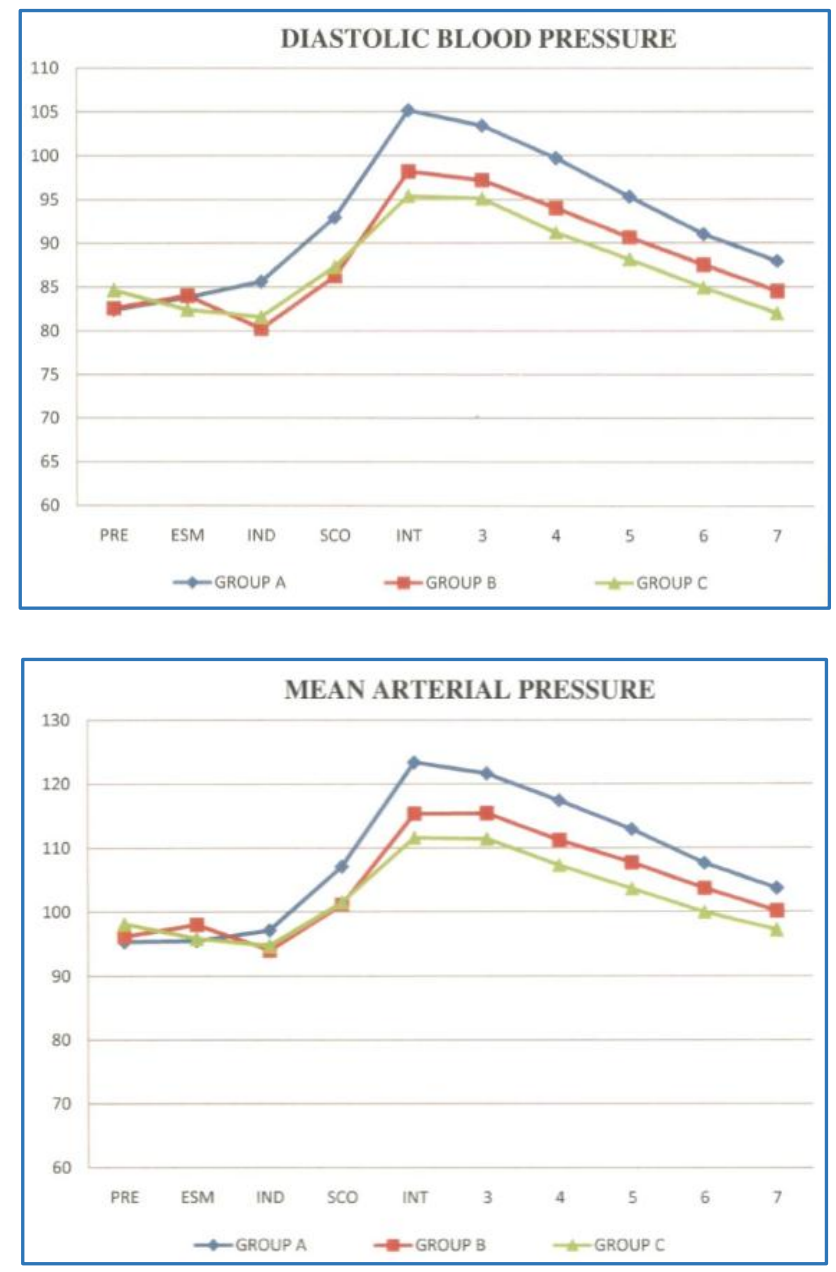

\begin{tabular}{|c|c|c|c|c|}
\hline Time & Group A & Group B & Group C & $P$ value \\
\hline Premed & $92.1 \pm 8.1$ & $90.3 \pm 5.2$ & $90.3 \pm 3.4$ & $>0.05$ \\
\hline Esmolol & $102.3 \pm 7.4$ & $94.4 \pm 2.6$ & $92.8 \pm 3.9$ & $<0.0001$ \\
\hline $\begin{array}{c}\text { At } \\
\text { Induction }\end{array}$ & $102.4 \pm 6.6$ & $90.55 \pm 3.8$ & $89.4 \pm 3.9$ & $<0.0001$ \\
\hline $\begin{array}{c}\text { After } \\
\text { Scoline }\end{array}$ & $98.7 \pm 6.8$ & $88.1 \pm 3.3$ & $87.6 \pm 6.5$ & $<0.0001$ \\
\hline $\begin{array}{c}\text { At } \\
\text { Intubation }\end{array}$ & $108.7 \pm 6.3$ & $96.1 \pm 3.6$ & $92.9 \pm 6.4$ & $<0.0001$ \\
\hline $\begin{array}{c}\text { At } 3 \\
\text { Minutes }\end{array}$ & $107.3 \pm 5.9$ & $94.1 \pm 4.0$ & $92.8 \pm 6.4$ & $<0.0001$ \\
\hline $\begin{array}{c}\text { At } 4 \\
\text { Minutes }\end{array}$ & $105.1 \pm 6.0$ & $94.1 \pm 4.2$ & $90.8 \pm 6.3$ & $<0.0001$ \\
\hline $\begin{array}{c}\text { At } 5 \\
\text { Minutes }\end{array}$ & $101.0 \pm 5.9$ & $91.55 \pm 4.3$ & $89.7 \pm 6.5$ & $<0.0001$ \\
\hline $\begin{array}{c}\text { At } 6 \\
\text { Minutes }\end{array}$ & $98.9 \pm 5.9$ & $89.85 \pm 4.3$ & $88.6 \pm 6.6$ & $<0.0001$ \\
\hline $\begin{array}{c}\text { At } 7 \\
\text { Minutes }\end{array}$ & $96.6 \pm 5.9$ & $88.15 \pm 4.4$ & $87.75 \pm 6.3$ & $<0.0001$ \\
\hline
\end{tabular}

\begin{tabular}{|c|c|c|c|c|}
\hline Time & Group A & Group B & Group C & P value \\
\hline Premed & $122.6 \pm 6.5$ & $124.05 \pm 5.8$ & $126.2 \pm 5.7$ & $>0.05$ \\
\hline Esmolol & $124.6 \pm 6.26$ & $125.65 \pm 6.3$ & $123.4 \pm 6.0$ & $>0.05$ \\
\hline $\begin{array}{c}\text { At } \\
\text { Induction }\end{array}$ & $126.4 \pm 6.6$ & $120.95 \pm 5.8$ & $122.4 \pm 6.6$ & $<0.05$ \\
\hline $\begin{array}{c}\text { After } \\
\text { Scoline }\end{array}$ & $137.8 \pm 6.4$ & $131.1 \pm 5.89$ & $130.5 \pm 6.3$ & $<0.05$ \\
\hline $\begin{array}{c}\text { At } \\
\text { Intubation }\end{array}$ & $160.9 \pm 7.7$ & $150.5 \pm 5.7$ & $145.15 \pm 5.3$ & $<0.0001$ \\
\hline
\end{tabular}

\begin{tabular}{|c|c|c|c|c|}
\hline $\begin{array}{c}\text { At 3 } \\
\text { Minutes }\end{array}$ & $159.2 \pm 7.6$ & $149.8 \pm 5.3$ & $144.6 \pm 4.9$ & $<0.0001$ \\
\hline $\begin{array}{c}\text { At 4 } \\
\text { Minutes }\end{array}$ & $154.1 \pm 6.8$ & $145.5 \pm 5.2$ & $139.9 \pm 4.8$ & $<0.0001$ \\
\hline $\begin{array}{c}\text { At 5 } \\
\text { Minutes }\end{array}$ & $148.1 \pm 6.5$ & $142.2 \pm 5.4$ & $135.6 \pm 4.6$ & $<0.0001$ \\
\hline $\begin{array}{c}\text { At 6 } \\
\text { Minutes }\end{array}$ & $141.7 \pm 6.48$ & $136.5 \pm 5.4$ & $131.3 \pm 4.6$ & $<0.0001$ \\
\hline $\begin{array}{c}\text { At 7 } \\
\text { Minutes }\end{array}$ & $135.6 \pm 6.3$ & $131.7 \pm 5.4$ & $127.5 \pm 4.3$ & $=0.0001$ \\
\hline \multicolumn{5}{|c|}{ Table 2: Mean Systolic Blood Pressure } \\
\hline \multicolumn{5}{|c|}{}
\end{tabular}

\begin{tabular}{|c|c|c|c|c|}
\hline Time & Group A & Group B & Group C & $P$ value \\
\hline Premed & $82.3 \pm 5.9$ & $82.6 \pm 5.5$ & $84.55 \pm 6.1$ & $>0.05$ \\
\hline Esmolol & $83.7 \pm 6.3$ & $84.0 \pm 5.0$ & $82.35 \pm 5.9$ & $>0.05$ \\
\hline $\begin{array}{c}\text { At } \\
\text { Induction }\end{array}$ & $85.5 \pm 6.3$ & $80.2 \pm 5.6$ & $81.55 \pm 5.0$ & $<0.05$ \\
\hline $\begin{array}{c}\text { After } \\
\text { Scoline }\end{array}$ & $92.9 \pm 5.3$ & $86.2 \pm 4.3$ & $87.3 \pm 5.1$ & $<0.0001$ \\
\hline $\begin{array}{c}\text { At } \\
\text { Intubation }\end{array}$ & $105.1 \pm 5.2$ & $98.2 \pm 4.4$ & $95.35 \pm 4.0$ & $<0.0001$ \\
\hline $\begin{array}{c}\text { At } 3 \\
\text { Minutes }\end{array}$ & $103.4 \pm 4.98$ & $97.2 \pm 4.13$ & $95.1 \pm 3.6$ & $<0.0001$ \\
\hline $\begin{array}{c}\text { At } 4 \\
\text { Minutes }\end{array}$ & $99.6 \pm 4.0$ & $93.95 \pm 4.1$ & $91.2 \pm 4.1$ & $<0.0001$ \\
\hline $\begin{array}{c}\text { At } 5 \\
\text { Minutes }\end{array}$ & $95.3 \pm 4.6$ & $90.65 \pm 4.1$ & $88.05 \pm 3.9$ & $<0.0001$ \\
\hline $\begin{array}{c}\text { At } 6 \\
\text { Minutes }\end{array}$ & $91.0 \pm 3.27$ & $87.5 \pm 4.3$ & $84.9 \pm 3.5$ & $<0.0001$ \\
\hline $\begin{array}{c}\text { At } 7 \\
\text { Minutes }\end{array}$ & $87.8 \pm 3.7$ & $84.4 \pm 4.1$ & $82.0 \pm 3.5$ & $<0.0001$ \\
\hline
\end{tabular}

\begin{tabular}{|c|c|c|c|c|}
\hline Time & Group A & Group B & Group C & P value \\
\hline Premed & $95.3 \pm 6.0$ & $96.1 \pm 5.1$ & $98.1 \pm 5.3$ & $>0.05$ \\
\hline Esmolol & $95.4 \pm 6.2$ & $98.0 \pm 4.9$ & $95.7 \pm 5.7$ & $>0.05$ \\
\hline $\begin{array}{c}\text { At } \\
\text { Induction }\end{array}$ & $97.1 \pm 6.7$ & $94.0 \pm 5.5$ & $94.7 \pm 5.6$ & $>0.05$ \\
\hline $\begin{array}{c}\text { After } \\
\text { Scoline }\end{array}$ & $107.1 \pm 5.8$ & $101.1 \pm 4.9$ & $101.5 \pm 5.0$ & $<0.05$ \\
\hline $\begin{array}{c}\text { At } \\
\text { Intubation }\end{array}$ & $123.3 \pm 5.8$ & $115.4 \pm 4.8$ & $111.6 \pm 4.3$ & $<0.0001$ \\
\hline $\begin{array}{c}\text { At 3 } \\
\text { Minutes }\end{array}$ & $121.6 \pm 5.6$ & $115.4 \pm 4.6$ & $111.4 \pm 4.4$ & $<0.0001$ \\
\hline $\begin{array}{c}\text { At 4 } \\
\text { Minutes }\end{array}$ & $117.4 \pm 4.3$ & $111.15 \pm 4.4$ & $107.3 \pm 4.7$ & $<0.0001$ \\
\hline $\begin{array}{c}\text { At 5 } \\
\text { Minutes }\end{array}$ & $112.8 \pm 4.9$ & $107.6 \pm 4.6$ & $103.5 \pm 4.0$ & $<0.0001$ \\
\hline $\begin{array}{c}\text { At 6 } \\
\text { Minutes }\end{array}$ & $107.5 \pm 3.6$ & $103.6 \pm 4.6$ & $99.9 \pm 3.7$ & $<0.0001$ \\
\hline $\begin{array}{c}\text { At 7 } \\
\text { Minutes }\end{array}$ & $103.6 \pm 4.1$ & $100.1 \pm 3.7$ & $97.1 \pm 3.6$ & $<0.0001$ \\
\hline \multicolumn{5}{|c|}{ Table 4: Mean Arterial Pressure } \\
\hline
\end{tabular}

\section{DISCUSSION}

Laryngoscopy and intubation produces haemodynamic stress response characterized by hypertension and tachycardia. This neuroendocrine response causes a variety of complications in patients with cardiac disease due to imbalance between myocardial oxygen supply and demand 
like ST changes, ventricular arrhythmias and pulmonary oedema. ${ }^{1}$

This is also hazardous in patients with vascular pathologies that cause weakening of the lining of the major arteries in particular cerebral and aortic aneurysms. In patients with hydrocephalus or intracranial mass lesions, the increase in cerebrospinal fluid pressure may produce transient impairment of cerebral perfusion.

Direct laryngoscopy that does not exceed 15 seconds duration is helpful in minimizing the blood pressure elevation evoked by this painful stimulus.

In view of the frequent occurrence of hypertension and tachycardia during laryngoscopy even in the normotensive individual, it is perhaps rather surprising that complications have not been met very often. Reason for this may be the transient nature of the hypertension, which usually lasts for less than ten minutes. It is possible however that some of the complications that occur during intubation or even later in the course of anaesthesia may be precipitated by an episode of hypertension and tachycardia following endotracheal intubation. 2,3

This reflex response may be diminished or modified locally, centrally or peripherally and attempts have been made to accomplish this with varying success by different techniques and agents. No effective drug has been found out so far to abolish this response. 4

Ebert TJ and Bernstein JS (1990).5,6 studied that haemodynamic response to Rapid sequence induction and intubation in healthy patients with a single bolus dose of Esmolol. They concluded that Esmolol $2 \mathrm{mg} / \mathrm{kg}$ bolus effectively attenuated heart rate, systolic blood pressure, diastolic blood pressure increases produced by laryngoscopy and intubation. In our study also, we took 2 minutes as the time for administering Esmolol prior to laryngoscopy and intubation.

Sheppard et al (1990).7,8 compared different bolus dose to Esmolol and concluded that attenuation of intubation response is adequate following $100 \mathrm{mg}$ of Esmolol.

Helfman SM et al (1991). ${ }^{9}$ compared the efficacy of Lidocaine, Fentanyl and esmolol to obtund the intubation responses and concluded that only esmolol provided constant and reliable part against increase in heart rate and systolic blood pressure accompanying laryngoscopy and intubation.

Miller D R et al,10 (1991) in their Canadian multicentre trial involving 548 patients concluded that $100 \mathrm{mg}$ bolus Esmolol is safe and effective agent. This dose of Esmolol combined with low dose of Fentanyl $(2-3 \mathrm{mcg} / \mathrm{kg})$ results in effective control of both heart rate and blood pressure while avoiding important side effect.

Ganbatz C L et al,11 (1991) also had similar results of Miller D R et al.

Vucovic M et al,12,13 (1992) studied about the use of Esmolol for management of cardiovascular responses to laryngoscopy and tracheal intubation and found that pressor response to laryngoscopy was significantly less marked in patients given esmolol 2 minutes before intubation, which was similar to our timing of drug administration.

Vucovic M et al (1992) concluded randomized control trial with $500 \mathrm{mcg} / \mathrm{kg} / \mathrm{min}$ for 2 minutes and maintenance $100 \mathrm{mcg} / \mathrm{kg} / \mathrm{min}$ till intubation and showed that heart rate, systolic blood pressure were significantly decreased in Esmolol group.
Kovac et al,14 (1992) concluded that in an eye patient with coronary artery disease or in any patient whom increase in heart rate may be detrimental, Esmolol may be a useful adjunct in combination with low-dose alfentanil to attenuate the increase in heart rate due to laryngoscopy and intubation.

Yuan L, Chia YY.15 (1994) studied the efficiency of bolus dose Esmolol in blunting the stress response comparing 100 $\mathrm{mg}$ Esmolol versus $200 \mathrm{mg}$ Esmolol. They concluded that both bolus dose of Esmolol could effectively attenuate the increase the heart rate, hypertension produced by laryngoscopy and intubation; furthermore, Esmolol $200 \mathrm{mg}$ presented a better haemodynamic stability than $100 \mathrm{mg}$ Esmolol. In our study Esmolol $1.5 \mathrm{mg} / \mathrm{kg}$ provided better haemodynamic control than Esmolol $1 \mathrm{mg} / \mathrm{kg}$ bolus.

Sharma S, Ghania A. ${ }^{16}$ (1995) also concluded adequate haemodynamic control was obtained with the administration of Esmolol bolus $2 \mathrm{mg} / \mathrm{kg}$.

Weist D et al, ${ }^{17}$ (1995) made a review of therapeutic efficacy and pharmacokinetic characteristics of Esmolol.

Singh H et al,18 (1995) in their study concluded that Lidocaine $1.5 \mathrm{mg} / \mathrm{kg}$ IV and Nitroglycerin $2 \mathrm{mcg} / \mathrm{kg}$ IV were effective in controlling the acute haemodynamic response following laryngoscopy and intubation. Esmolol $1.4 \mathrm{mg} / \mathrm{kg}$ was significantly more effective than either Lidocaine or Nitroglycerin in controlling heart rate or mean arterial pressure increase during intubation.

Sharma et al,19 (1996) compared the ability of different bolus doses of Esmolol to blunt the haemodynamic response to laryngoscopy and intubation in treated hypertensive patients concluded that Esmolol $100 \mathrm{mg}$ given as bolus is effective as well as safe in blunting the response. In our study it was Esmolol $1.5 \mathrm{mg} / \mathrm{kg}$ IV bolus was effective and safe in blunting the response.

Feng C K et al,20 (1996) concluded that Esmolol only could reliably offer protection against increase in both heart rate and systolic blood pressure. Low dose Fentanyl $(2 \mathrm{mcg} / \mathrm{kg}$ ) prevented heart rate, but no increase in heart rate and 2 $\mathrm{mg} / \mathrm{kg}$ lidocaine had no effect.

Wang L et al,21,22 (1999) concluded that $1.2 \mathrm{mg} / \mathrm{kg}$ bolus of Esmolol is effective and safe. We also used Esmolol in the range of $0.5 \mathrm{mg} / \mathrm{kg}$ to $1.5 \mathrm{mg} / \mathrm{kg}$, which was also safe.

Bensky et al,23,24 (2000) in their study concluded that small dose of Esmolol may block the increase in heart rate and blood pressure resulting from laryngoscopy and intubation.

Figueredo, E. Garcia-Fuentes EM.25 (2001) compared the results of 38 randomized control trial involving different regimen and doses of Esmolol and found that the most effective regimen was a loading dose of $500 \mathrm{mcg} / \mathrm{kg} / \mathrm{min}$ over 4 minutes, followed by continuous infusion dose of 200 $300 \mathrm{mcg} / \mathrm{kg} / \mathrm{min}$.

Analysis of the length of our study showed that Esmolol $1.5 \mathrm{mg} / \mathrm{kg}$ was more effective in attenuating the heart rate response to laryngoscopy and intubation.

Also, Esmolol $1.5 \mathrm{mg} / \mathrm{kg}$ was effective in attenuating the blood pressure increase accompanying laryngoscopy and intubation.

\section{CONCLUSION}

On taking into consideration the criteria which we chose to study the haemodynamic changes expected, we found that the dose of Esmolol $1.5 \mathrm{mg} / \mathrm{kg}$ (Group C) to be effective in 
attenuating the haemodynamic responses during laryngoscopy and endotracheal intubation with no major adverse effects of Esmolol.

\section{ACKNOWLEDGEMENTS}

We are very grateful to the professors and assistant professors of the Department of General Surgery.

We are extremely thankful to the assistant professors and the postgraduates of the Department of Anaesthesiology for their help in carrying out this study.

We are thankful to the Institutional Ethical Committee for their guidance and approval for this study. Last but not the least, we thank all our patients for willingly submitting themselves for this study.

We also wish to state that no financial or material support was obtained for this study.

\section{REFERENCES}

1. Goodman, Gilman's. The pharmacological basis of therapeutics. Adrenergic agonist and antagonist Chapter 10,$2006 ; 11^{\text {th }}$ ed:271-91.

2. Miller's Anaesthesia. Pharmacology of Esmolol Chapter 16,$2005 ; 6^{\text {th }}$ ed:653-8.

3. Robert K Stoelting. Anaesthesia and co-existing disease. Anaesthesia and Analgesia Chapter 5, 2003; $4^{\text {th }}$ edn:p 102.

4. King BD, Harris LC, Creinfenstein FE, et al. Circulatory responses to direct laryngoscopy and endotracheal intubation. British Journal of Anaesthesiology 1951;65:216-9.

5. Ebert JP, Pearson JD, Gelman S, et al. Circulatory response to laryngoscopy-the comparative effects of placebo, fentanyl and esmolol. Canadian Journal of Anaesthesia 1989;36(3 Pt 1):301-6.

6. Ebert TJ, Bernstein JS, Stowe DF, et al. Attenuation of haemodynamic response to rapid sequence induction and intubation in healthy patients with a single bolus of esmolol. Journal of Clinical Anaesthesia 1990;2(4):24352.

7. Sheppard S, Eagle CJ, Strunin L. A bolus dose to esmolol attenuating tachycardia and hypertension after tracheal intubation. Canadian Journal of Anaesthesia 1990;37(2):202-5.

8. Oxorn D, Konx W, Hill J. Bolus doses of esmolol for the prevention of perioperative hypertension and tachycardia. Canadian Journal of Anaesthesia 1990;37(2):206-9.

9. Helfman SM, Gold MI, Delisser EA. Which drug prevents tachycardia and hypertension associated with tracheal intubation: lidocaine, fentanyl, esmolol. Anaesthesia and Analgesia 1989;68:101-4.

10. Miller DR, Maurtineaux RJ, Wynands JE, et al. Bolus administration of esmolol for controlling the haemodynamic response to tracheal intubation: the Canadian multicenter trial. Canadian Journal of Anaesthesia 1991;38(7):849-58.

11. Ganbatz CL, Wehner RJ. Effect of esmolol and fentanyl in controlling rise in heart rate and blood pressure during intubation. AANA Journal 1991;59(1):19-26.
12. Vucovic M, Pordy GM, Ellid FR. Esmolol hydrochloride for management cardiovascular response to laryngoscopy and tracheal intubation. British Journal of Anaesthesia 1992;68(5):529-30.

13. Chung KS, Sinatra RS, Halevy JD, et al. A comparison of fentanyl, esmolol and their combination for blunting the haemodynamic responses during rapid sequence intubation. Canadian Journal of Anaesthesia 1992;39(8):74-9.

14. Kovac AL, Bennets PS, Ohara S, et al. Effects of esmolol on haemodynamic and intra ocular pressure response to succinyl choline and intubation following low dose alfentanil premedication. Journal of Clinical Anaesthesia 1992;4(4):315-20.

15. Yuan L, Chia YY, Jan KT, et al. The effect of single bolus dose of esmolol for controlling tachycardia and hypertension during laryngoscopy and tracheal intubation. Acta Anaesthesiology Scandinavia 1994;32(3):147-52.

16. Sharma S, Ghani A, Win N, et al. Two bolus doses of esmolol for attenuation of haemodynamic response to tracheal intubation. Medical Journal of Malaysia 1995;50(4):372-6.

17. Weist D. Esmolol. A review of its therapeutic efficacy and pharmacokinetics characteristics. Clinical Pharmacokinetics 1995;28(3):190-202.

18. Singh H, Vichitrejpaisal P, Gaines GY, et al. Comparative effects of lidocaine, esmolol, nitroglycerin in modulating response to intubation. Journal of Clinical Anaesthesia 1995;7(1):5-8.

19. Sharma S, Mitra S, Grover VK, et al. Esmolol blunts the haemodynamic response to tracheal intubation in treated hypertensive patients. Canadian journal of Anaesthesia 1996;43(8):778-82.

20. Feng CK, Chan KH, Liu KN, et al. Comparison of lidocaine, fentanyl, esmolol for attenuating cardiovascular response to laryngoscopy and intubation. Acta Anaesthesiology Scandinavia 1996;34(2):61-7.

21. Kindler $\mathrm{CH}$, Schumacher PG, Schenider MC, et al. Effects of IV lidocaine and/or esmolol on haemodynamic response to laryngoscopy and intubation: a double-blind, controlled clinical trial. Journal of Clinical Anaesthesia 1996;8(6):491-6.

22. Wang L, Luo A, Wu X. Bolus administration of esmolol for preventing the haemodynamic response to tracheal intubation: a multicentre clinical study. Zhonghua yi xue za zhi 1999;79(11):828-31.

23. Atlee JL, Dhamee MS, Olund TL, et al. Use of esmolol, nicardipine or their combination to blunt haemodynamic changes after intubation. Anaesthesia-Analgesia 2000;90(2):280-5.

24. Bensky KP, Donafine-Spencer L, Hertz GE. Effect of esmolol on laryngoscopy and intubation. AANA Journal 2000;68(5):437-42.

25. Figueredo E, Garcia-Fuentes EM. Assessment of the efficacy of esmolol on the haemodynamic changes induced by laryngoscopy and tracheal intubation: a meta-analysis. Acta Anaesthesiology Scandinavia 2001;45(8):1011-22. 